\title{
FRAMEWORK PARA DETERMINAÇÃO DAS BARREIRAS À GESTÃO DO CONHECIMENTO
}

\section{FRAMEWORK FOR DETERMINATION OFBARRIERS TO THE MANAGEMENT OF KNOWLEDGE}

\author{
Maria Clara da Cunha Bezerra*E-mail: mariaclarabezerraa@hotmail.com \\ Rafael Targino Dantas de Lima* E-mail: rafaeltarginoeng@gmail.com \\ Márcia Maria de Figueiredo Maciel ${ }^{\star}$ E-mail: marciamp30@hotmail.com \\ Ricardo Moreira da Silva* E-mail: ricardomoreira0203@hotmail.com \\ *Universidade Federal da Paraíba (UFPB), João Pessoa, PB
}

Resumo: No contexto global, o conhecimento tem sido usado como um recurso nas organizações e reconhecido como uma fonte de vantagem competitiva sustentável no campo comercial, o que levou as empresas a adotar novas posturas voltadas para o gerenciamento do conhecimento (KM) e aprendizagem. No entanto, para alcançar esta nova e melhorada forma de gestão, é necessário superar várias barreiras. Este artigo tem como objetivo apresentar uma estrutura que aponte as barreiras para a implantação da gestão do conhecimento (GC) nas organizações. Este framework foi construído com base em uma revisão sistemática da literatura na base de dados "Web of Science", na qual foram utilizadas a técnica de análise de clusters e a análise de conteúdo, resultando em um modelo / lista de barreiras para GC agrupadas em categorias individuais, organizacionais, tecnológicas e de categoria cruzadas. Este framework contribui para a ciência, uma vez que consegue reunir uma série de tipos de barreiras em um único quadro, e também para as organizações por ser uma ferramenta fácil de usar, permitindo a rápida identificação de várias barreiras que envolvem a implementação do gerenciamento de conhecimento. Para ilustrar a eficácia do framework, um estudo de caso foi realizado em um setor administrativo da instituição pública de ensino superior da Paraíba, onde foi possível avaliar barreiras no setor e também o grau de correlação entre elas.

Palavras-chave: Barreiras. Gestão do Conhecimento. Framework.

Abstract: In the global context, knowledge has been used as a resource in organizations and recognized as a source of sustainable competitive advantage in the business field, which led the companies to adopt new postures focused on knowledge management (KM) and learning. However, in order to achieve this new and improved way of management, its necessary to overcome several barriers. this article aims to present a framework that points out the barriers to the implantation of the knowledge management $(\mathrm{KM})$ in organizations. This framework was constructed based on a systematic review of the literature in the "Web of Science" database, in which the clusters analysis technique and the content analysis were used, resulting in a barriers model / list to KM grouped in individual, organizational, technological and cross-category barriers. This framework contributes to science since it manages to bring together a range of types of barriers in a single framework, and also for the organizations for being an easy to use tool, allowing the rapid identification of several barriers that hamper knowledge management implementation. To illustrate the framework's efficacy, a case study was carried out in an administrative sector of a Paraiba's higher education public institution of, where it was possible to evaluate barriers in the sector, and also the degree of correlation between them

Keywords: Barriers. Knowledge management. Framework. 


\section{INTRODUÇÃO}

Mudanças sociais, econômicas e tecnológicas vêm redesenhando a atividade produtiva, na qual o conhecimento passa a ser visto como principal recurso na criação de vantagens competitivas e no sucesso dos negócios (STEFANOVITZ; SEIDO NAGANO, 2007). Para melhorar a rentabilidade, as empresas necessitam realizar da melhor forma as atividades que geram valor para organização. Assim, é preciso promover a criação do conhecimento e, faz-se imprescindível identificar os conhecimentos que a empresa necessita para atender aos novos desafios, como também, buscar fontes fornecedoras de conhecimento (MICHELON, 2006).

As empresas que buscam eficiência e eficácia em seus processos administrativos adotam a gestão do conhecimento (GC) como uma prática, uma vez que é possível com esse gerenciamento formalizar conhecimentos e a melhoria contínua dos processos envolvidos (OLIVA, 2014).

Muniz e Nakano (2009) afirmam que o conceito de GC vem sendo discutido desde o final da última década do milênio passado. Esses autores definem GC como uma atuação sistematizada, formal e deliberada no sentido de capturar, preservar, compartilhar e (re)utilizar os conhecimentos tácitos e explícitos, que são desenvolvidos a partir das atividades de rotina e de melhoria dos processos produtivos, de modo a gerar resultados mensuráveis para as empresas e para as pessoas.

Segundo Szezerbicki et al. (2006) a GC reorganiza e potencializa os fatores de produtividade, inovação, competitividade e relacionamento das empresas no campo em que atuam.

Riege (2005) afirma que em uma economia baseada no conhecimento, os ativos intangíveis são cada vez mais um fator diferencial para competição, especialmente em indústrias de serviços. Hong, Suh e Koo (2011) corroboram com a afirmação, colocando que o conhecimento é o capital intelectual de uma organização e é fundamental para se obter vantagem competitiva.

No entanto, ainda segundo Hong, Suh e Koo (2011) um grande desafio para as empresas é conseguir incentivar o compartilhamento de conhecimento dentro de uma organização. As empresas são empurradas a buscar soluções, e se 
conscientizar do papel de conhecimento e sua ligação com a obtenção de vantagens competitivas mais sustentáveis (REIS, MILAN, 2009).

Apesar do crescente significado das práticas de compartilhamento de conhecimento para organizações em busca de competitividade e desempenho do mercado, várias barreiras dificultam o alcance dos objetivos da Gestão do Conhecimento (RIEGE, 2005).

Um grande número de autores concorda que gerir conhecimento não é uma tarefa fácil, e identificaram que uma série de barreiras são atreladas a esta prática, através de diferentes tipos de estudos e aplicações práticas (BENMOUSSA, 2009; LIN et al.,2008; MCLAUGHLIN, PATON E MACBETH, 2008; RIEGE, 2005; BURES, 2003; THOBEN, WEBER, WUNRAM, 2002; KROGH, ICHIJO E NONAKA, 2001; LUGGER E KRAUS, 2001; DISTERER, 2001; BARSON et al., 2000)

Contudo, não se encontrou na literatura nenhuma pesquisa que aglutinasse as diversas possíveis barreiras à implantação e efetivação da GC, permitindo assim, uma identificação de barreiras de forma simples e como fonte para um estudo em profundidade.

Neste sentido, este artigo teve como objetivo construir um framework das barreiras que permeiam a GC na vasta literatura sobre o tema, com a identificação, análise, descarte e agrupamento destas barreiras, apontando cada barreira com a sua descrição, classificação e autores que as identificaram e utilizaram em seus trabalhos.

Além dessa contribuição, como forma de mostrar que o framework pode ser usado, desenvolveu-se uma aplicação em um estudo de caso, para identificar quais barreiras à GC são percebidas em um setor administrativo de uma instituição pública de ensino superior da Paraíba.

\section{METODOLOGIA}

Para o desenvolvimento do referencial teórico em torno da estruturação conceitual e identificação das barreiras relacionadas à GC que possibilitou a construção do framework, realizou-se uma pesquisa sistemática da literatura na "Web of Science" e outros artigos foram adicionados a amostra a partir das citações e referências consideradas relevantes. 
Na Web of Science utilizaram-se os termos de busca "barrier" e "knowledge management' como tópicos, resultando em 5259 ocorrências, em seguida refinou-se a amostra para tipos de documentos em artigos e review e nas categorias do Web of Science: "engineering multidisciplinary, management engineering manufacturing, business, engineering industrial, public administration" o que resultou em 502 artigos.

Aproveitou-se deste resultado inicial para a geração de um gráfico de análise de redes no programa VOSviewer, apresentado na figura 1, a fim de se ter um panorama geral sobre as pesquisas relacionadas à GC e barreiras a ela associadas.

O gráfico mostra as co-ocorrências das palavras chaves utilizadas pelos autores da amostra, cada palavra-chave precisou aparecer um mínimo de três vezes entre as pesquisas. Pode-se observar a partir da figura 1 que os processos de transferência, criação e aquisição do conhecimento aparecem com relevância, como também, questões atreladas a estratégias de gestão, inovação, entre outras categorias que podem servir para a determinação de diferentes temas de pesquisa a serem estudados.

A validade e confiabilidade dessa pesquisa sistemática foi baseada no esquema traçado por Castro (2017) onde: (a) houve a triangulação de fontes ao se construir o quadro de cada grupo de barreiras onde buscou-se mais de uma referência bibliográfica; (b) houve a revisão por pelo menos dois pares (um doutor e um mestrando) da descrição da barreira encontrada e (c) houve revisão por informantes-chaves, uma vez que dois graduados revisaram o quadro final das barreiras, quando tiveram completo acesso aos dados coletados.

Após análise de cluster, que direcionou o foco do framework para o centro de figura, realizou-se a leitura dos títulos e resumos da amostra para eliminação das pesquisas fora do escopo a que o estudo se propôs. Após esta fase a amostra foi reduzida a 16 artigos e a partir da leitura integral destes, foram adicionadas à amostra 8 pesquisas a partir das referências dos artigos iniciais. Assim a amostra final resultou em 24 artigos, onde se realizou a análise de conteúdo dos artigos. 
Figura 1: Análise de palavras-chaves sobre barreiras à

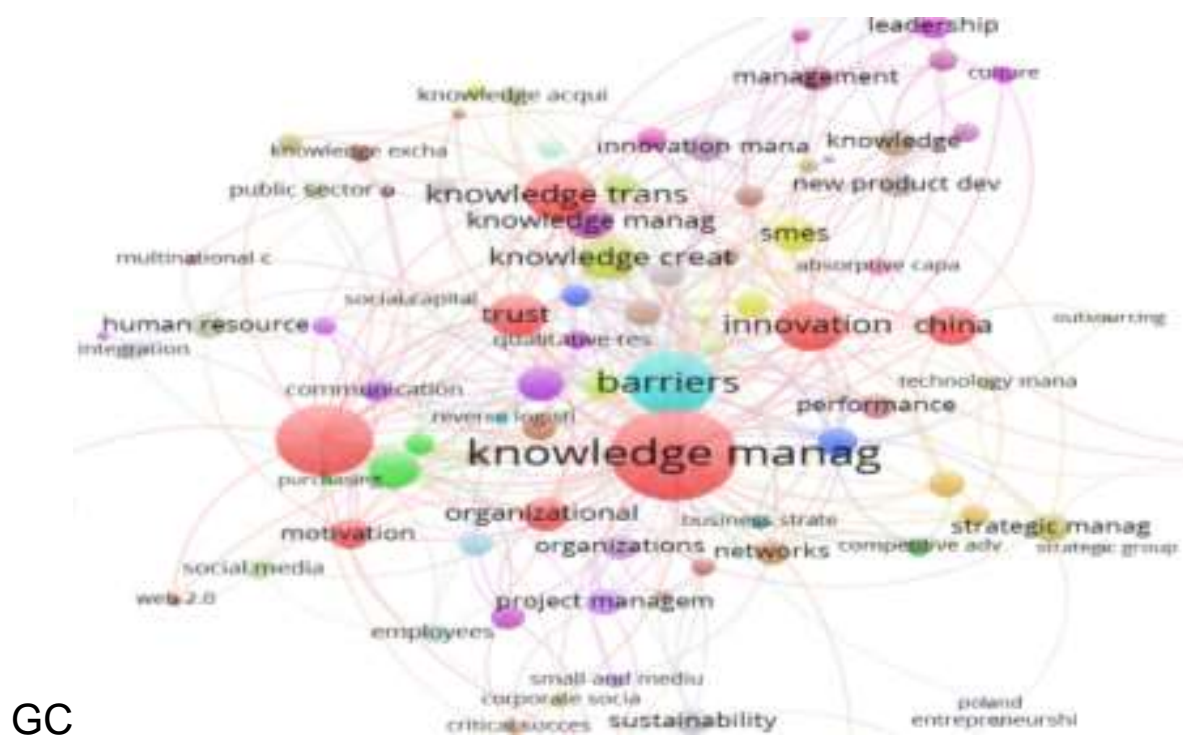

Fonte: Elaborado pelos autores (2017)

Partindo para a caracterização da amostra final desta pesquisa, o quadro 1 apresenta os títulos, autores, ano e periódico de cada publicação.

Quadro 1: Artigos analisados na pesquisa

\begin{tabular}{|l|l|l|}
\hline \multicolumn{1}{|c|}{ Autor /Ano } & \multicolumn{1}{|c|}{ Periódico } & \multicolumn{1}{c|}{ Títulos } \\
\hline $\begin{array}{l}\text { Leela Damodaran \& } \\
\text { Wendy Olphert (2000) }\end{array}$ & $\begin{array}{l}\text { Behaviour \& } \\
\text { Information } \\
\text { Technology }\end{array}$ & $\begin{array}{l}\text { Barreiras e facilitadores para o uso do } \\
\text { conhecimento - Sistemas de gestão. }\end{array}$ \\
\hline $\begin{array}{l}\text { David W., De Long, } \\
\text { Liam Fahey (2000) }\end{array}$ & $\begin{array}{l}\text { Academy Ot } \\
\text { Management } \\
\text { Executive. }\end{array}$ & Diagnosticando barreiras culturais à GC. \\
\hline $\begin{array}{l}\text { Richard J, Gillian Foster, } \\
\text { Thomas Struck, Svetan } \\
\text { Ratchev, Kulwant } \\
\text { Pawar, Frithj Weber, } \\
\text { Michael Wunram (2000) }\end{array}$ & $\begin{array}{l}\text { International } \\
\text { conference on } \\
\text { e-business and } \\
\text { e-work }\end{array}$ & $\begin{array}{l}\text { Barreiras inter e intra-organizacionais para } \\
\text { compartilhar conhecimento na cadeia de } \\
\text { fornecimento estendida. }\end{array}$ \\
\hline $\begin{array}{l}\text { Kurt Martin Lugger, } \\
\text { Hebert Kraus (2001) }\end{array}$ & $\begin{array}{l}\text { Journal of } \\
\text { Universal } \\
\text { Computer } \\
\text { Science. }\end{array}$ & Dominando as barreiras humanas na GC. \\
\hline Georg Disterer (2001) & $\begin{array}{l}\text { Hawaii } \\
\text { International } \\
\text { Conference on } \\
\text { System } \\
\text { Sciences }\end{array}$ & $\begin{array}{l}\text { Obstáculos individuais e sociais à } \\
\text { transferência de conhecimento. }\end{array}$ \\
\hline $\begin{array}{l}\text { Klaus-Dieter Thoben, } \\
\text { Frithjof Weber, Michael } \\
\text { Wunram (2002) }\end{array}$ & $\begin{array}{l}\text { Studies in } \\
\text { Informatics and } \\
\text { Control }\end{array}$ & Barreiras na GC e Abordagens Pragmáticas. \\
\hline Vladimír Bures (2003) & Cultural Barriers & Barreiras culturais em compartilhamento do \\
\hline
\end{tabular}

Revista Produção Online. Florianópolis, SC, v. 18, n. 4, p. 1398-1421, 2018. 


\begin{tabular}{|c|c|c|}
\hline & $\begin{array}{l}\text { in Knowledge } \\
\text { Sharing }\end{array}$ & conhecimento \\
\hline $\begin{array}{l}\text { Eric Ras, Martin } \\
\text { Memmel, Stephan } \\
\text { Weibelzah (2005) }\end{array}$ & $\begin{array}{l}\text { Professional } \\
\text { Knowledge } \\
\text { Management }\end{array}$ & $\begin{array}{l}\text { Integração do E-Learning e GC - Barreiras, } \\
\text { Soluções e Problemas Futuros. }\end{array}$ \\
\hline Andreas Riege (2005) & $\begin{array}{l}\text { Journal of } \\
\text { Knowledge } \\
\text { Management }\end{array}$ & $\begin{array}{l}\text { Três dúzias de barreiras de compartilhamento } \\
\text { de conhecimento que os gerentes devem } \\
\text { considerar. }\end{array}$ \\
\hline Lee, O. (2006) & $\begin{array}{l}\text { Cyberpsycholog } \\
\text { y \& Behavior }\end{array}$ & $\begin{array}{l}\text { Barreiras psicológicas para manter o } \\
\text { conhecimento - Sistemas de gestão. }\end{array}$ \\
\hline $\begin{array}{l}\text { Chinho Lin, Bertram } \\
\text { Tan, Shofang Chang } \\
(2008)\end{array}$ & $\begin{array}{l}\text { Information \& } \\
\text { Management }\end{array}$ & $\begin{array}{l}\text { Um modelo exploratório de barreiras de fluxo } \\
\text { de conhecimento nas organizações de saúde. }\end{array}$ \\
\hline $\begin{array}{l}\text { Stephen Mclaughlin, } \\
\text { Robert A. Paton Douglas } \\
\text { K. Macbeth (2008) }\end{array}$ & $\begin{array}{l}\text { Journal of } \\
\text { knowledge } \\
\text { Management }\end{array}$ & $\begin{array}{l}\text { Impacto da barreira na aprendizagem } \\
\text { organizacional dentro de organizações } \\
\text { complexas. }\end{array}$ \\
\hline $\begin{array}{l}\text { Stephen Hanwk,Weijun } \\
\text { Zheng, Robert W. Zmud } \\
\text { (2009) }\end{array}$ & $\begin{array}{l}\text { MIS Quarterly } \\
\text { Executive }\end{array}$ & $\begin{array}{l}\text { Superando o conhecimento - Transferência } \\
\text { Barreiras no gerenciamento de infraestrutura } \\
\text { Outsourcing: lições de um estudo de caso. }\end{array}$ \\
\hline BenMoussa (2009) & $\begin{array}{l}\text { World Academy } \\
\text { of Science, } \\
\text { Engineering and } \\
\text { Technology }\end{array}$ & $\begin{array}{l}\text { Barreiras para a GC: A Estrutura teórica e } \\
\text { uma revisão de Casos Industriais }\end{array}$ \\
\hline $\begin{array}{l}\text { M. Milosz, E. Milosz } \\
(2010)\end{array}$ & $\begin{array}{l}\text { Actual Problems } \\
\text { of Economics }\end{array}$ & $\begin{array}{l}\text { Fatores e barreiras de sucesso crítico para } \\
\text { aplicação do conhecimento - sistemas de } \\
\text { gestão nas pessoas polandesas. }\end{array}$ \\
\hline $\begin{array}{l}\text { Itiel E. Dror,Tamas } \\
\text { Makany E Jonathan } \\
\text { Kemp (2010) }\end{array}$ & Dyslexia & $\begin{array}{l}\text { Superando obstáculos de aprendizagem } \\
\text { através do Conhecimento Gestão. }\end{array}$ \\
\hline $\begin{array}{l}\text { Daegeun Hong, Euiho } \\
\text { Suh, Choonghyo Koo } \\
\text { (2011) }\end{array}$ & $\begin{array}{l}\text { Expert Systems } \\
\text { With } \\
\text { Applications }\end{array}$ & $\begin{array}{l}\text { Desenvolver estratégias para superar } \\
\text { barreiras ao compartilhamento de } \\
\text { conhecimento com base em }\end{array}$ \\
\hline $\begin{array}{l}\text { Chinho Lin, Ju-Chuan } \\
\text { Wu, David C. Yen } \\
\text { (2012) }\end{array}$ & $\begin{array}{l}\text { Information and } \\
\text { Management }\end{array}$ & $\begin{array}{l}\text { Explorando barreiras ao fluxo de } \\
\text { conhecimento em diferentes sistemas de } \\
\text { conhecimento - Estágios de maturidade. }\end{array}$ \\
\hline Fabio Lotti Oliva (2014) & $\begin{array}{l}\text { Journal of } \\
\text { Knowledge } \\
\text { Management }\end{array}$ & $\begin{array}{l}\text { Barreiras, práticas e modelo de maturidade da } \\
\text { GC. }\end{array}$ \\
\hline $\begin{array}{l}\text { Sachin K. Patil, Ravi } \\
\text { Kant (2014) }\end{array}$ & $\begin{array}{l}\text { Expert Systems } \\
\text { With } \\
\text { Applications }\end{array}$ & $\begin{array}{l}\text { Uma estrutura difusa de AHP-TOPSIS para } \\
\text { classificar as soluções de adoção de } \\
\text { gerenciamento de conhecimento na Cadeia de } \\
\text { suprimentos para superar suas barreiras. }\end{array}$ \\
\hline $\begin{array}{l}\text { Henri Pirkkalainen, Jan } \\
\text { M. Pawlowski (2014) }\end{array}$ & $\begin{array}{l}\text { Computers in } \\
\text { Human } \\
\text { Behavior }\end{array}$ & $\begin{array}{l}\text { Gestão global do conhecimento social - } \\
\text { Compreender as barreiras para os } \\
\text { trabalhadores globais utilizando software } \\
\text { social. }\end{array}$ \\
\hline $\begin{array}{l}\text { David Rodríguez } \\
\text { Gómez, Joaquín Gairín } \\
\text { (2015) }\end{array}$ & $\begin{array}{l}\text { Knowledge } \\
\text { Management } \\
\text { Research \& } \\
\text { Practice }\end{array}$ & $\begin{array}{l}\text { Descrevendo criação e gestão de } \\
\text { conhecimento em organizações educacionais: } \\
\text { barreiras e facilitadores. }\end{array}$ \\
\hline $\begin{array}{l}\text { Changiz Valmohammadi } \\
\text { Ali Ghassemi (2016) }\end{array}$ & $\begin{array}{l}\text { VINE Journal of } \\
\text { Information and } \\
\text { Knowledge }\end{array}$ & $\begin{array}{l}\text { Identificação e priorização das barreiras da } \\
\text { implementação do gerenciamento do } \\
\text { conhecimento usando Fuzzy Analytical }\end{array}$ \\
\hline
\end{tabular}




\begin{tabular}{|l|l|l|}
\hline & $\begin{array}{l}\text { Management } \\
\text { Systems }\end{array}$ & $\begin{array}{l}\text { Network Process: Um estudo de caso sobre o } \\
\text { contexto iraniano. }\end{array}$ \\
\hline $\begin{array}{l}\text { Leila Shahmoradi, Reza } \\
\text { Safdari, Zakieh Piri, } \\
\text { Arezoo Mahmodabadi; } \\
\text { Somayeh Shahmoradi, } \\
\begin{array}{l}\text { Ahmadreza Farzaneh } \\
\text { Nejad (2017) }\end{array}\end{array}$ & $\begin{array}{l}\text { The Health Care } \\
\text { Manager }\end{array}$ & $\begin{array}{l}\text { Compartilhamento de conhecimento como } \\
\text { base poderosa para barreiras e soluções de } \\
\text { gerenciamento. }\end{array}$ \\
\hline
\end{tabular}

Fonte: Elaborado pelos autores (2017)

A literatura utilizada apresenta uma gama de barreiras relacionadas à GC, que resultou na construção do framework mostrado no quadro 2 (a seguir) onde as mesmas foram agrupadas em barreiras individuais, organizacionais, tecnológicas e categoria cruzada de Barson et al. (2000). Para cada barreira apresentou-se uma descrição e os autores que as identificaram e as utilizaram em suas pesquisas.

Assim, o elenco das barreiras fornece respaldo teórico para construção do Framework que segue a seguinte metodologia:

1) Selecionar as possíveis barreiras existentes na organização a ser pesquisada através de entrevista semiestruturada, a pelo menos 5 pessoas e não mais que 10 da organização, como forma de primeiro filtro das barreiras. Ou seja, seguindo apenas um check list citando as barreiras, o pesquisador consegue retirar algumas barreiras que o quadro apresenta, mas que não estaria presente na organização. Nessa etapa o feeling do pesquisador e do grupo piloto é o critério de redução.

2) Elaboração de um questionário com as barreiras que não foram excluídas na primeira etapa. Neste questionário, utiliza-se a escala Likert que varia de 1 à 5 sendo 1 (inexistente); 2 (pouco presente); 3 (presente moderadamente); 4 (muito presente); 5 (totalmente presente). Aplicado a 28 funcionários do setor administrativo em estudo.

3) Utilização como parâmetro para avaliar a incidência das barreiras à moda das respostas dos itens. Aplica-se o teste Qui-quadrado de comparação de múltiplas proporções para verificar a representatividade do parâmetro utilizado.

4) Realiza-se o cálculo das correlações de cada item para o grupo estudado baseado no método de Spearman, que é adequado para verificar associações entre variáveis ordinais.

5) Analise das barreiras e das associações existentes 
Assim, apesar de utilizar técnicas estatísticas consagradas e simples, 0 framework funciona e é inédito porque tem sólida base teórica inicial num quadro de barreiras construído com sustentação científica.

Então, por fim, metodologicamente esse trabalho se encera mostrando a utilização do framework construído, quando se realizou um estudo de caso em um setor administrativo de uma instituição pública de ensino superior na Paraíba.

\section{BARREIRAS À GC}

A busca pela eficiência no uso de recursos através da aplicação do conhecimento existente, assim como a busca de eficácia na melhoria dos resultados através da criação de novos conhecimentos podem ser afetados por barreiras que são estabelecidas em cada etapa do processo de GC (OLIVA, 2014). De acordo com BenMoussa (2009) diversas barreiras inter-relacionadas impedem as iniciativas de gestão de conhecimento e dificultam o pleno valor desses esforços.

Segundo Marondin, Saurin (2015), barreiras tem como definição qualquer problema técnico, organizacional ou social que tenha como consequência o comprometimento da eficiência e eficácia do processo de implantação. Para Copetti, Saurin, Soliman (2016), as barreiras podem ser consideradas o oposto dos fatores de sucesso.

Ainda segundo Wunran, Foster e Mottaghian (2000) as barreiras à GC podem ser consideradas como todas as coisas pertencentes aos problemas humanos, organizacionais e/ou tecnológicos que restrinja a gestão intra ou inter-organizacional do conhecimento. O tópico 4 traz um estudo aprofundado sobre esse assunto, foco desta pesquisa.

$\mathrm{Na}$ literatura as barreiras do conhecimento são classificadas com relação a diferentes aspectos. Autores como Krogh, Ichijo e Nonaka (2001) e Lugger e Kraus (2001) destacam as barreiras à criação e ao compartilhamento do conhecimento em dois tipos: barreiras individuais e barreiras organizacionais. Prontamente, Bures (2003) e Disterer (2001) classificam como barreiras individuais e sociais, sendo que esta última se enquadra no que os outros autores chamam de organizacionais.

Outros autores convergem na classificação das barreiras em três grupos, que além as barreiras humanas e organizacionais, consideram também as barreiras 
tecnológicas. (BARSON et al., 2000; THOBEN; WEBER; WUNRAM, 2002; RIEGE, 2005).

Barson et al. (2000) ainda acrescentam à sua classificação as barreiras de categorias cruzadas, como aquelas que se relacionam com mais de um tipo das classificações anteriores (tecnológicas, humanas e organizacionais)

Oliva (2014) classifica as barreiras como organizacionais, humanas e acrescenta as barreiras ambientais, no entanto analisa que estas indicam perdas menos relevantes quando comparadas as perdas causadas por barreiras humanas e organizacionais.

Szulanski (1996) apresentou as principais barreiras que impedem a transferência de conhecimento nas organizações e agrupa em quatro conjuntos: barreiras inerentes as características do conhecimento; barreiras inerentes à fonte de conhecimento; barreiras inerentes ao destinatário deste conhecimento; e barreiras inerentes ao contexto cultural. Lin et al. (2008) em sua pesquisa em organizações no setor de saúde utilizou esta classificação, acrescentando as barreiras ao contexto de fluxo do conhecimento.

McLaughlin, Paton e Macbeth (2008) contemplam cinco tipos de barreiras: barreira quanto à motivação ao compartilhamento do conhecimento; barreira quanto ao impacto da transferência de conhecimento forçado/solicitado; barreira quanto ao impacto das relações interpessoais sobre o conhecimento; barreira quanto ao impacto da estrutura organizacional sobre o conhecimento e barreira quanto ao impacto de uma abordagem codificada no compartilhamento do conhecimento.

Tanto a classificação de Szulanski (1996) como de McLaughlin, Paton e Macbeth (2008) apesar de analisar as barreiras sobre diferentes vertentes, a grande parte de suas barreiras convergem com as determinadas por outros autores que classificam quanto à natureza da própria barreira, tecnológicas, humanas e organizacionais.

BenMoussa (2009) classifica as barreiras naquelas que envolve as áreas organizacionais de planejamento, capacitação e motivação, onde uma das principais barreiras relacionadas ao planejamento está ligada à falta de metas, de iniciativas, de GC mal definida. Com relação à capacitação, um número de estudos mostrou que a tecnologia pode ser uma barreira significativa nos programas de gerenciamento de conhecimento. E o autor complementa que embora exista um 
consenso na literatura sobre o papel fundamental da tecnologia na GC, muitos estudos sugerem que a maior barreira está na motivação as pessoas a contribuir com o conhecimento e compartilhar seu know-how.

O segundo tipo de barreiras que BenMoussa (2009) coloca é mais pessoal e se relaciona com as atitudes e comportamentos distintos dos usuários ao adotar sistemas de gerenciamento de conhecimento.

Toda esta análise de conteúdo dos estudos, resultou na construção do quadro 2, que nomeamos de Framework das Barreiras à GC, que contém uma síntese todas as barreiras encontradas.

Quadro 2: FRAMEWORK DAS BARREIRAS À GC

\begin{tabular}{|c|c|c|c|}
\hline \multicolumn{4}{|c|}{ ETAPA 1} \\
\hline ETAPA 2 & Construção d & um questionário norteado pelas barreir & as não excluídas \\
\hline ETAPA 3 & Aplicação do & questionário e teste Qui-quadrado & \\
\hline ETAPA 4 & \begin{tabular}{l|l} 
APA 4 & Teste de Spe
\end{tabular} & arman & \\
\hline \multicolumn{4}{|c|}{ Analise das barreiras e associações existentes } \\
\hline \multicolumn{4}{|c|}{ QUADRO GERAL DAS BARREIRAS } \\
\hline \multicolumn{4}{|c|}{ BARREIRAS TECNOLÓGICAS } \\
\hline $\mathrm{N}$ & BARREIRAS & DESCRIÇÃO & AUTORES \\
\hline 1 & $\begin{array}{l}\text { Indisponibilidade } \\
\text { tecnológica }\end{array}$ & $\begin{array}{l}\text { A tecnologia ainda é incapaz de fornecer } \\
\text { uma única solução de conhecimento. As } \\
\text { soluções geralmente são uma } \\
\text { combinação de de aplicativos } \\
\text { compartilhados. }\end{array}$ & Barson et al. (2000) \\
\hline 2 & $\begin{array}{l}\text { Sistemas legados e } \\
\text { sua incompatibilidade }\end{array}$ & $\begin{array}{l}\text { Juntar os sistemas de vários } \\
\text { departamentos } \\
\text { interoperabilidade difícil de alcançar. }\end{array}$ & $\begin{array}{l}\text { Barson et al. (2000) } \\
\text { Lugger e Kraus } \\
\text { (2001) Riege (2005) } \\
\end{array}$ \\
\hline 3 & $\begin{array}{l}\text { Incompatibilidade de } \\
\text { sistemas }\end{array}$ & $\begin{array}{l}\text { Sistemas de diferentes setores e } \\
\text { departamentos são incompatíveis }\end{array}$ & $\begin{array}{l}\text { Barson et al. (2000) } \\
\text { Riege (2005) }\end{array}$ \\
\hline 4 & $\begin{array}{l}\text { Rápida mudança de } \\
\text { tecnologia }\end{array}$ & $\begin{array}{l}\text { Novas tecnologias sendo lançadas e } \\
\text { tornando as utilizadas obsoletas }\end{array}$ & Barson et al. (2000) \\
\hline 5 & $\begin{array}{l}\text { Falta de suporte } \\
\text { técnico }\end{array}$ & $\begin{array}{l}\text { Falta de suporte técnico obstrui as rotinas } \\
\text { de trabalho e os fluxos de comunicação. }\end{array}$ & Riege (2005) \\
\hline 6 & $\begin{array}{l}\text { Falta de familiaridade } \\
\text { e treinamento em } \\
\text { sistemas }\end{array}$ & $\begin{array}{l}\text { Usuários não conheçam as ferramentas } \\
\text { disponíveis para o compartilhamento do } \\
\text { conhecimento, e que compreendam os } \\
\text { recursos informacionais disponíveis nos } \\
\text { seus mais variados meios. }\end{array}$ & Riege (2005) \\
\hline 7 & $\begin{array}{l}\text { Falta de integração de } \\
\text { sistemas tecnológicos } \\
\text { e processos. }\end{array}$ & $\begin{array}{l}\text { Falta de compatibilidade entre diversos } \\
\text { sistemas e processos informáticos. }\end{array}$ & Riege (2005) \\
\hline
\end{tabular}




\begin{tabular}{|c|c|c|c|}
\hline 8 & $\begin{array}{l}\text { Irreais expectativas } \\
\text { dos funcionários em } \\
\text { relação à capacidade } \\
\text { da tecnologia }\end{array}$ & $\begin{array}{l}\text { O desajuste entre os requisitos de } \\
\text { necessidade dos indivíduos e os sistemas } \\
\text { e processos de TI integrados restringem } \\
\text { as práticas de compartilhamento; }\end{array}$ & Riege (2005) \\
\hline 9 & $\begin{array}{l}\text { Eficiência e eficácia } \\
\text { do sistema }\end{array}$ & $\begin{array}{l}\text { A tecnologia muitas vezes não suporta } \\
\text { os requisitos das pessoas }\end{array}$ & Barson et al. (2000) \\
\hline \multicolumn{4}{|c|}{ BARREIRAS INDIVIDUAIS } \\
\hline $\mathrm{N}$ & BARREIRAS & DESCRIÇÃO & AUTORES \\
\hline 10 & Resistencia interna & $\begin{array}{l}\text { O desejo de proteger os interesses da } \\
\text { empresa, restringindo o conhecimento } \\
\text { que está sendo transferido para fontes } \\
\text { externas. }\end{array}$ & Barson et al. (2000) \\
\hline 11 & $\begin{array}{l}\text { Interesse próprio/ } \\
\text { competitividade }\end{array}$ & $\begin{array}{l}\text { Busca-se defender seus interesses, } \\
\text { nãohá disponibilidade de compartilhar } \\
\text { conhecimento com seus possíveis } \\
\text { concorrentes. }\end{array}$ & $\begin{array}{l}\text { Barson et al. (2000) } \\
\text { Riege (2005) }\end{array}$ \\
\hline 12 & Falta de confiança & $\begin{array}{l}\text { Se não há confiança na informação que } \\
\text { se recebe é improvável que se uso e falta } \\
\text { de confiança a quem se transfere o } \\
\text { conhecimento por usar ou obter crédito } \\
\text { de forma injusta. }\end{array}$ & $\begin{array}{l}\text { Barson et al. (2000) } \\
\text { Lugger e Kraus } \\
\text { (2001) Riege (2005) }\end{array}$ \\
\hline 13 & $\begin{array}{l}\text { Risco/ falta de } \\
\text { segurança }\end{array}$ & $\begin{array}{l}\text { Relacionado com a propriedade do } \\
\text { conhecimento. O compartilhamento tem } \\
\text { um elemento de risco e falta de confiança }\end{array}$ & $\begin{array}{l}\text { Barson et al. (2000) } \\
\text { Riege (2005) }\end{array}$ \\
\hline 14 & Medo de exploração & $\begin{array}{l}\text { Achar que as pessoas sempre vão querer } \\
\text { algo em troca por compartilharem seu } \\
\text { conhecimento }\end{array}$ & $\begin{array}{l}\text { Barson et al. (2000) } \\
\text { Lugger e } \text { Kraus } \\
\text { (2001) }\end{array}$ \\
\hline 15 & $\begin{array}{c}\text { Medo de } \\
\text { contaminação }\end{array}$ & $\begin{array}{l}\text { Quando organizações com marca de } \\
\text { mercado tem medo de juntar } \\
\text { conhecimentos com pessoas que } \\
\text { percebem de mais baixo mercado }\end{array}$ & Barson et al. (2000) \\
\hline 16 & Diferentes idiomas & $\begin{array}{l}\text { Em algumas empresas o idioma usado } \\
\text { em uma seção, departamento ou divisão } \\
\text { é ininteligível para os outros. }\end{array}$ & $\begin{array}{lr}\text { Thoben, } & \text { Weber e } \\
\text { Wunram } & (2002) \\
\text { Bures (2003) Riege } \\
(2005) & \text { Disterer } \\
(2001) & \\
\end{array}$ \\
\hline 17 & $\begin{array}{l}\text { Medo de pena / } \\
\text { crítica/ medo de } \\
\text { perder perfil }\end{array}$ & $\begin{array}{l}\text { A apresentação de ideias não claramente } \\
\text { definidas é muitas vezes considerada } \\
\text { uma fraqueza, por interpretações erradas } \\
\text { sobre o conhecimento }\end{array}$ & $\begin{array}{l}\text { Barson et al. (2000) } \\
\text { Lugger e Kraus } \\
(2001) \text { Thoben, } \\
\text { Weber e Wunram } \\
\text { (2002) Riege (2005) } \\
\end{array}$ \\
\hline 18 & Roubo de ideias & $\begin{array}{l}\text { O receio de que a ideia de um } \\
\text { empregado possa ser tomada por outro } \\
\text { que tenha o reconhecimento e } \\
\text { recompensas por ela }\end{array}$ & $\begin{array}{l}\text { Thoben, Weber e } \\
\text { Wunram (2002) }\end{array}$ \\
\hline 19 & $\begin{array}{l}\text { Pensamento } \\
\text { proprietário em } \\
\text { diferentes níveis/ } \\
\text { desigualdade de } \\
\text { status }\end{array}$ & $\begin{array}{lrr}\text { Os funcionários de nível inferior e médio } \\
\text { geralmente } & \text { acumulam } & \text { seus } \\
\text { conhecimentos } & \text { intencionalmente } & \text { sobre } \\
\text { seus superiores } & & \end{array}$ & $\begin{array}{l}\text { Barson et al. (2000) } \\
\text { Riege (2005) }\end{array}$ \\
\hline
\end{tabular}




\begin{tabular}{|c|c|c|c|}
\hline 20 & $\begin{array}{l}\text { Ceticismo para a } \\
\text { partilha de } \\
\text { conhecimentos/ }\end{array}$ & $\begin{array}{l}\text { Não acreditar que a partilha do } \\
\text { conhecimento possa agregar valor para } \\
\text { si. }\end{array}$ & $\begin{array}{l}\text { Barson et al. (2000) } \\
\text { Shahmoradi et al } \\
\text { (2017) Riege (2005) }\end{array}$ \\
\hline 21 & Medo de perder poder & $\begin{array}{l}\text { O conhecimento é visto como poder para } \\
\text { aquele que o detêm }\end{array}$ & $\begin{array}{l}\text { Barson et al. (2000) } \\
\text { Shahmoradi et al } \\
(2017) \text { Bures (2003) } \\
\text { Riege (2005) } \\
\text { Disterer (2001) }\end{array}$ \\
\hline 22 & $\begin{array}{l}\text { Medo de perder } \\
\text { recursos/ emprego }\end{array}$ & $\begin{array}{l}\text { Se as estruturas internas de } \\
\text { empresa se tornarem públicas os } \\
\text { membros da equipe poderão ser } \\
\text { cortados. }\end{array}$ & $\begin{array}{l}\text { Barson et al. (2000) } \\
\text { Ruege (2005) }\end{array}$ \\
\hline 23 & $\begin{array}{c}\text { Medo de perder a } \\
\text { estabilidade da } \\
\text { empresa / posição no } \\
\text { mercado }\end{array}$ & $\begin{array}{l}\text { Medo de compartilhar informações com } \\
\text { concorrentes e perder vantagem }\end{array}$ & Barson et al. (2000) \\
\hline 24 & $\begin{array}{l}\text { Medo de tornar-se } \\
\text { redundante }\end{array}$ & $\begin{array}{l}\text { Não ser mais importante depois de dar a } \\
\text { informação ao sistema }\end{array}$ & Barson et al. (2000) \\
\hline 25 & $\begin{array}{l}\text { Medo de perder a } \\
\text { confidencialidade }\end{array}$ & $\begin{array}{l}\text { Alimentar informações a clientes e } \\
\text { fornecedores e chegar aos competidores }\end{array}$ & Barson et al. (2000) \\
\hline 26 & $\begin{array}{c}\text { Falta de terreno } \\
\text { comum / Falta de } \\
\text { conjuntos de } \\
\text { habilidades múltiplas } \\
\end{array}$ & $\begin{array}{l}\text { As ideias não convergem e não há } \\
\text { terreno para se compartilhar }\end{array}$ & $\begin{array}{l}\text { Barson et al. (2000) } \\
\text { Shahmoradi et al } \\
(2017) \\
\text { BenMoussa (2009) } \\
\end{array}$ \\
\hline 27 & $\begin{array}{l}\text { Falta de } \\
\text { comunicação/ } \\
\text { comunicação } \\
\text { ineficiente }\end{array}$ & $\begin{array}{l}\text { A falta de contatos e interações entre } \\
\text { fontes de conhecimento e receptores, que } \\
\text { muitas vezes não funcionam lado a lado } \\
\text { ou na mesma equipe. }\end{array}$ & $\begin{array}{l}\text { Sahmoradi et al } \\
\text { (2017) Lugger e } \\
\text { Kraus (2001) Oliva } \\
\text { (2014) Riege (2005) } \\
\text { BenMoussa (2009) } \\
\end{array}$ \\
\hline 28 & $\begin{array}{l}\text { Cultura de trabalhar } \\
\text { sozinho/ Falta de } \\
\text { cultura de partilha }\end{array}$ & $\begin{array}{l}\text { Não há incentivo para colaboração e } \\
\text { trabalhos em equipe }\end{array}$ & $\begin{array}{l}\text { Sahmoradi et al } \\
\text { (2017) Lugger e } \\
\text { Kraus (2001) Oliva } \\
\text { (2014) Riege (2005) } \\
\end{array}$ \\
\hline 29 & Especialização & $\begin{array}{l}\text { O medo de ser conhecido como } \\
\text { especialista desestimula a partilha de } \\
\text { conhecimento }\end{array}$ & $\begin{array}{l}\text { Sahmoradi et al } \\
(2017) ; \text { BenMoussa } \\
(2009)\end{array}$ \\
\hline 30 & $\begin{array}{c}\text { Ameaça à } \\
\text { autoimagem }\end{array}$ & $\begin{array}{l}\text { Conhecimento e autoimagem estão } \\
\text { fortemente ligados e surge à resistência } \\
\text { em alguns indivíduos }\end{array}$ & $\begin{array}{l}\text { Krogh, Ichijo } \\
\text { Nonaka (2001) }\end{array}$ \\
\hline 31 & $\begin{array}{l}\text { Capacidade de } \\
\text { acomodação }\end{array}$ & $\begin{array}{l}\text { Acomodar novos conceitos é um desafio } \\
\text { enorme para uns, que depende da } \\
\text { validação e da justificação da nova } \\
\text { crença }\end{array}$ & $\begin{array}{l}\text { Krogh, Ichijo } \\
\text { Nonaka (2001) }\end{array}$ \\
\hline 32 & $\begin{array}{l}\text { Más experiências no } \\
\text { passado }\end{array}$ & $\begin{array}{l}\text { Erros passados afetam a partilha de } \\
\text { conhecimento. }\end{array}$ & $\begin{array}{l}\text { Lugger e Kraus } \\
\text { (2001) Riege (2005) }\end{array}$ \\
\hline 33 & $\begin{array}{l}\text { Falta sensibilidade a } \\
\text { lidar com os outros }\end{array}$ & $\begin{array}{l}\text { Não respeitar os sentimentos e emoções } \\
\text { dos envolvidos na partilha do } \\
\text { conhecimento }\end{array}$ & $\begin{array}{l}\text { Lugger e Kraus } \\
(2001)\end{array}$ \\
\hline 34 & Falta de tempo & $\begin{array}{l}\text { Não ter tempo suficiente para administrar } \\
\text { conhecimento. Percepção de que } \quad 0 \\
\text { gerenciamento do conhecimento é algo }\end{array}$ & $\begin{array}{l}\text { Lugger e Kraus } \\
\text { (2001) Riege (2005) } \\
\text { BenMoussa (2009) } \\
\end{array}$ \\
\hline
\end{tabular}




\begin{tabular}{|c|c|c|c|}
\hline & & $\begin{array}{l}\text { "extra" e não algo integrado ao seu } \\
\text { ambiente de trabalho diário. }\end{array}$ & \\
\hline 35 & Preconceito & $\begin{array}{l}\text { Preconceitos entre gênero, idades, } \\
\text { cargos, setores que impedem a GC }\end{array}$ & $\begin{array}{l}\text { Lugger e Kraus } \\
(2001)\end{array}$ \\
\hline 36 & $\begin{array}{l}\text { Falta de competência } \\
\text { da equipe }\end{array}$ & $\begin{array}{l}\text { Equipe sem kow-how e empenho } \\
\text { suficientes }\end{array}$ & Oliva (2014) \\
\hline 37 & Falta de interesse & $\begin{array}{l}\text { Os indivíduos não se interessam e assim } \\
\text { não facilitam o compartilhamento }\end{array}$ & Oliva (2014) \\
\hline 38 & Incerteza & $\begin{array}{l}\text { Em vários âmbitos, por exemplo: os } \\
\text { funcionários mais jovens e inexperientes } \\
\text { sentem incertezas, por não saberem } \\
\text { analisar se seus conhecimentos são } \\
\text { importantes para os outros. }\end{array}$ & $\begin{array}{l}\text { Bures (2003), } \\
\text { Disterer (2001) }\end{array}$ \\
\hline 39 & $\begin{array}{l}\text { Ilusão de privação de } \\
\text { recompensa }\end{array}$ & $\begin{array}{l}\text { Achar que podem perder suas } \\
\text { recompensas de trabalho, porque dão } \\
\text { seus conhecimentos e experiência a } \\
\text { outra pessoa que pode ser } \\
\text { recompensado em seu lugar }\end{array}$ & Bures (2003) \\
\hline 40 & $\begin{array}{l}\text { Diferença entre } \\
\text { consciência e } \\
\text { conhecimento }\end{array}$ & $\begin{array}{l}\text { Possuir apenas consciência do problema, } \\
\text { o que ocasiona não querer ouvir o que } \\
\text { julgam já saber. }\end{array}$ & Bures (2003) \\
\hline 41 & Conflito de motivos & $\begin{array}{l}\text { Conflitos psicológicos, frustações } \\
\text { pessoais. }\end{array}$ & Bures (2003) \\
\hline 42 & $\begin{array}{c}\text { Receio de } \\
\text { constrangimentos }\end{array}$ & $\begin{array}{l}\text { Quando as ideias e opiniões são } \\
\text { ridicularizadas, criticadas ou ignoradas, } \\
\text { as pessoas se sentem ameaçadas e } \\
\text { punidas por contribuir. }\end{array}$ & Disterer (2001) \\
\hline 43 & Medo de revelação & $\begin{array}{l}\text { Passar o conhecimento aos colegas ou } \\
\text { colocar os resultados de trabalho em um } \\
\text { banco de dados proclama que esse } \\
\text { conhecimento tem um certo valor e } \\
\text { raridade. }\end{array}$ & $\begin{array}{l}\text { Bures (2003) } \\
\text { Disterer (2001) }\end{array}$ \\
\hline \multicolumn{4}{|c|}{ BARREIRAS ORGANIZACIONAIS } \\
\hline $\mathrm{N}$ & BARREIRAS & DESCRIÇÃO & AUTORES \\
\hline 44 & $\begin{array}{l}\text { Fomentar canais de } \\
\text { comunicação } \\
\text { estabelecidos onde } \\
\text { há informações } \\
\text { insuficientes } \\
\end{array}$ & $\begin{array}{l}\text { Os canais de comunicação entre colegas } \\
\text { de diferentes empresas devem ser } \\
\text { mantidos e promovidos, resultando em } \\
\text { altos esforços. }\end{array}$ & 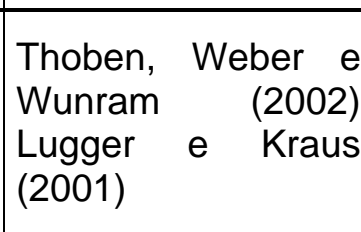 \\
\hline 45 & $\begin{array}{c}\text { Custos de } \\
\text { gerenciamento de } \\
\text { transferência de } \\
\text { conhecimento }\end{array}$ & $\begin{array}{l}\text { Estudos identificam custos aumentados } \\
\text { devido à cooperação com fornecedores } \\
\text { incapazes e custos de coordenação } \\
\text { organizacional. }\end{array}$ & Barson et al. (2000) \\
\hline 46 & $\begin{array}{l}\text { Proteção de } \\
\text { conhecimento } \\
\text { proprietário }\end{array}$ & 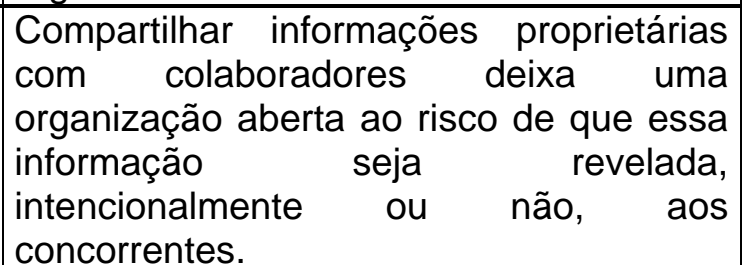 & $\begin{array}{l}\text { Barson et al. (2000) } \\
\text { Riege (2005) }\end{array}$ \\
\hline
\end{tabular}




\begin{tabular}{|c|c|c|c|}
\hline 47 & Distância & $\begin{array}{l}\text { Para transferir e compartilhar } \\
\text { conhecimento, é necessário um meio } \\
\text { aberto de comunicação. }\end{array}$ & Barson et al. (2000) \\
\hline 48 & $\begin{array}{c}\text { Falta de consciência } \\
\text { de estratégias de GC } \\
\text { e instrumentos/ } \\
\text { paradigmas } \\
\text { incoerentes } \\
\end{array}$ & $\begin{array}{l}\text { As empresas não têm uma explicação } \\
\text { explícita - Estratégia de gerenciamento } \\
\text { de conhecimento implementada, nem } \\
\text { determinou } \\
\text { correspondentes. }\end{array}$ & $\begin{array}{l}\text { Thoben, Weber e } \\
\text { Wunram (2002) } \\
\text { Bures (2003) Riege } \\
\text { (2005) }\end{array}$ \\
\hline 49 & Altos investimentos & $\begin{array}{l}\text { Construir parcerias intensivas } \\
\text { clientes eom } \\
\text { quantidades significativas de tempo e } \\
\text { dinheiro. }\end{array}$ & $\begin{array}{l}\text { Thoben, Weber e } \\
\text { Wunram (2002) }\end{array}$ \\
\hline 50 & $\begin{array}{l}\text { Indisponibilidade } \\
\text { de indivíduos }\end{array}$ & $\begin{array}{l}\text { Dificuldade em rastrear as pessoas } \\
\text { quando deseja falar com elas. Isso } \\
\text { resulta em atrasos de tempo procurando } \\
\text { por um indivíduo específico. }\end{array}$ & $\begin{array}{l}\text { Thoben, Weber e } \\
\text { Wunram (2002) }\end{array}$ \\
\hline 51 & $\begin{array}{l}\text { Diferentes horários de } \\
\text { trabalho }\end{array}$ & $\begin{array}{l}\text { As diferenças temporais geralmente } \\
\text { limitam a comunicação a um pequeno } \\
\text { período de tempo e, portanto, a meios de } \\
\text { comunicação indiretos. }\end{array}$ & $\begin{array}{l}\text { Thoben, Weber e } \\
\text { Wunram (2002) }\end{array}$ \\
\hline 52 & $\begin{array}{l}\text { Falta de linguagem } \\
\text { legítima }\end{array}$ & $\begin{array}{l}\text { Abrange a necessidade de uma } \\
\text { linguagem comum e especial como } \\
\text { analogias e metáforas para externalizar o } \\
\text { conhecimento tácito. }\end{array}$ & $\begin{array}{l}\text { Krogh, Ichijo } \\
\text { Nonaka (2001) }\end{array}$ \\
\hline 53 & $\begin{array}{c}\text { Historias } \\
\text { organizacionais }\end{array}$ & $\begin{array}{l}\text { O novo é interpretado sempre dentro da } \\
\text { velha perspectiva. }\end{array}$ & $\begin{array}{l}\text { Krogh, Ichijo } \\
\text { Nonaka (2001) }\end{array}$ \\
\hline 54 & $\begin{array}{c}\text { Regras, } \\
\text { Procedimentos e } \\
\text { Paradigmas } \\
\text { relacionados ao } \\
\text { trabalho/ Faltam } \\
\text { mecanismos formais } \\
\text { e informais } \\
\end{array}$ & $\begin{array}{l}\text { Os procedimentos da organização podem } \\
\text { barrar a criação de conhecimento } \\
\text { gerando paradigmas e modelos que se } \\
\text { tornam enraizados, principalmente se os } \\
\text { paradigmas forem inflexíveis e os valores } \\
\text { rígidos demais. }\end{array}$ & $\begin{array}{l}\text { Ichijo e Nonaka } \\
\text { (2001); Shahmoradi } \\
\text { et al (2017) Lugger } \\
\text { e Kraus (2001) } \\
\text { Disterer (2001) }\end{array}$ \\
\hline 55 & $\begin{array}{l}\text { Fatores relacionados } \\
\text { ao espaço de trabalho }\end{array}$ & $\begin{array}{l}\text { O ambiente de trabalho físico e layout } \\
\text { das áreas de trabalho restringem práticas } \\
\text { efetivas de compartilhamento. }\end{array}$ & $\begin{array}{l}\text { Sahmoradi et al } \\
\text { (2017) Riege (2005) }\end{array}$ \\
\hline 56 & $\begin{array}{l}\text { Condições sociais e } \\
\text { politicas }\end{array}$ & $\begin{array}{l}\text { As condições sociais e políticas de uma } \\
\text { organização pode reprimir a GC }\end{array}$ & $\begin{array}{l}\text { Sahmoradi et al } \\
(2017)\end{array}$ \\
\hline 57 & Hierarquias rígidas & $\begin{array}{l}\text { As fortes empresas hierárquicas } \\
\text { impedem a comunicação interfuncional, } \\
\text { tanto mais cooperação quanto } \\
\text { compartilhamento de conhecimento. }\end{array}$ & $\begin{array}{ll}\text { Lugger e } & \text { Kraus } \\
\text { (2001) Bures } & (2003) \\
\text { Riege } & (2005) \\
\text { Disterer } & (2001)\end{array}$ \\
\hline 58 & $\begin{array}{l}\text { Falta de incentivo/ } \\
\text { falta de motivação }\end{array}$ & $\begin{array}{l}\text { Falta da comunicação por parte da } \\
\text { liderança e gestores sobre os benefícios } \\
\text { de se compartilhar conhecimento }\end{array}$ & $\begin{array}{lr}\text { Oliva (2014) Riege } \\
(2005) & \text { Disterer } \\
(2001) ; & \text { BenMoussa } \\
(2009) & \\
\end{array}$ \\
\hline 59 & $\begin{array}{l}\text { Subestimar os níveis } \\
\text { mais baixos }\end{array}$ & $\begin{array}{l}\text { Essa atitude leva os trabalhadores do } \\
\text { conhecimento apenas como receptores } \\
\text { de informações passivas. }\end{array}$ & Bures (2003) \\
\hline
\end{tabular}




\begin{tabular}{|c|c|c|c|}
\hline 60 & Emoções & $\begin{array}{l}\text { As emoções afetam a vontade dos } \\
\text { funcionários de compartilhar } \\
\text { conhecimento com qualquer um. }\end{array}$ & Bures (2003) \\
\hline 61 & $\begin{array}{l}\text { Má avaliação da base } \\
\text { de conhecimento do } \\
\text { outro }\end{array}$ & $\begin{array}{l}\text { O remetente não conseguir estimar } 0 \\
\text { estado e o tamanho da base de } \\
\text { conhecimento do receptor }\end{array}$ & Bures (2003) \\
\hline 62 & $\begin{array}{l}\text { Evasão/evitação de } \\
\text { conflitos }\end{array}$ & $\begin{array}{l}\text { Esforços para evitar mudanças e também } \\
\text { não arriscar muito. }\end{array}$ & $\begin{array}{l}\text { Bures (2003) } \\
\text { Disterer (2001) }\end{array}$ \\
\hline \multicolumn{4}{|c|}{ BARREIRAS DE CATEGORIA CRUZADA } \\
\hline $\mathrm{N}$ & BARREIRAS & DESCRIÇÃO & AUTORES \\
\hline 63 & Recursos existentes & 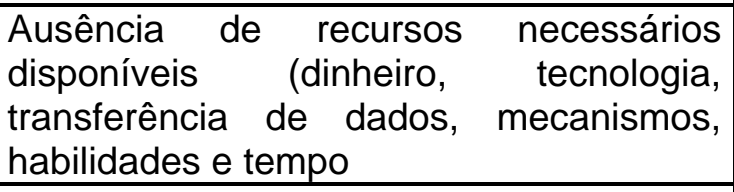 & $\begin{array}{l}\text { Barson et al. (2000) } \\
\text { Riege (2005) }\end{array}$ \\
\hline 64 & $\begin{array}{l}\text { A necessidade de } \\
\text { recompensas }\end{array}$ & $\begin{array}{l}\text { Os funcionários veem que a partilha } \\
\text { significa ganhos imediatos. }\end{array}$ & $\begin{array}{l}\text { Barson et al. (2000) } \\
\text { Riege (2005) }\end{array}$ \\
\hline 65 & Cultura & $\begin{array}{l}\text { A cultura corporativa existente não } \\
\text { oferece suporte suficiente para o } \\
\text { compartilhamento de práticas }\end{array}$ & $\begin{array}{l}\text { Barson et al. (2000) } \\
\text { Lugger e Kraus } \\
\text { (2001) Bures (2003) } \\
\text { Riege (2005); } \\
\text { BenMoussa (2009) }\end{array}$ \\
\hline
\end{tabular}

Fonte: Elaborado pelos autores (2017)

Assim, o framework construído foi baseado na descrição das barreiras que foram encontradas através de vasta pesquisa e agrupadas e classificadas de acordo com a convergência da maioria dos autores analisados.

\section{RESULTADOS DO ESTUDO DE CASO}

Seguindo as etapas propostas pelo framework, na primeira etapa realizou-se uma redução das variáveis segundo entrevista piloto com cinco pessoas da organização, sendo eliminadas as barreiras 13, 16, 23 e 38. Depois, construiu-se um questionário em cima das barreiras restantes.

Buscou-se então um parâmetro que pudesse representar as respostas do grupo acerca das barreiras. O parâmetro utilizado foi à moda das respostas dos itens.

Aplicou-se o teste Qui-quadrado de comparação de múltiplas proporções para verificar a representatividade do parâmetro utilizado. Tendo como hipótese nula que a proporção de respondentes nas 5 respostas é igual, uma vez que, como justificativa ao uso do teste temos que se as proporções são iguais a moda não pode ser representativa das respostas do grupo. Assim, foram eliminados os itens cujo 
valor "p" estivesse acima de 0,05. Logo, como resultado obteve-se 16 itens (barreiras à GC) eliminados. O quadro 3 apresenta esses resultados.

Quadro 3 - Aplicação do framework - Moda das respostas e resultado do teste Qui-quadrado de comparação de múltiplas proporções

\begin{tabular}{|c|c|c|c|c|c|c|c|c|}
\hline \multirow[t]{2}{*}{ Item } & \multicolumn{5}{|c|}{ Proporções de respondentes na escala } & \multirow[t]{2}{*}{ Moda } & \multicolumn{2}{|c|}{$\begin{array}{c}\text { Teste de } \\
\text { comparação das } \\
\text { proporções }\end{array}$} \\
\hline & 1 & 2 & 3 & 4 & 5 & & Estatística & Valor $\mathrm{p}$ \\
\hline 1 & $10,7 \%$ & $32,1 \%$ & $46,4 \%$ & $7,1 \%$ & $3,6 \%$ & 3 & 23,93 & 0,0001 \\
\hline 2 & $3,6 \%$ & $50,0 \%$ & $21,4 \%$ & $17,9 \%$ & $7,1 \%$ & 2 & 23,48 & 0,0001 \\
\hline 3 & $10,7 \%$ & $25,0 \%$ & $42,9 \%$ & $17,9 \%$ & $3,6 \%$ & 3 & 15,89 & 0,0032 \\
\hline 4 & $10,7 \%$ & $39,3 \%$ & $32,1 \%$ & $10,7 \%$ & $7,1 \%$ & 2 & 15,00 & 0,0047 \\
\hline 5 & $21,4 \%$ & $50,0 \%$ & $21,4 \%$ & $3,6 \%$ & $3,6 \%$ & 2 & 25,27 & 0,0000 \\
\hline 6 & $7,1 \%$ & $28,6 \%$ & $28,6 \%$ & $32,1 \%$ & $3,6 \%$ & 4 & 12,77 & 0,0125 \\
\hline 7 & $7,1 \%$ & $35,7 \%$ & $25,0 \%$ & $28,6 \%$ & $3,6 \%$ & 2 & 13,66 & 0,0085 \\
\hline 8 & $7,1 \%$ & $21,4 \%$ & $50,0 \%$ & $21,4 \%$ & $0,0 \%$ & 3 & 14,48 & 0,0023 \\
\hline 9 & $0,0 \%$ & $39,2 \%$ & $35,7 \%$ & $17,9 \%$ & $7,1 \%$ & 2 & 10,29 & 0,0163 \\
\hline 10 & $3,6 \%$ & $21,4 \%$ & $25,0 \%$ & $46,4 \%$ & $3,6 \%$ & 4 & 22,14 & 0,0002 \\
\hline 11 & $7,1 \%$ & $28,6 \%$ & $28,6 \%$ & $25,0 \%$ & $10,7 \%$ & 2 & 7,41 & 0,1157 \\
\hline 12 & $10,7 \%$ & $25,0 \%$ & $39,3 \%$ & $21,4 \%$ & $3,6 \%$ & 3 & 13,21 & 0,0103 \\
\hline 14 & $14,3 \%$ & $32,1 \%$ & $35,7 \%$ & $17,9 \%$ & $0,0 \%$ & 3 & 4,95 & 0,1753 \\
\hline 15 & $14,3 \%$ & $50,0 \%$ & $21,4 \%$ & $7,1 \%$ & $7,1 \%$ & 2 & 22,14 & 0,0002 \\
\hline 17 & $7,1 \%$ & $50,0 \%$ & $21,4 \%$ & $21,4 \%$ & $0,0 \%$ & 2 & 14,48 & 0,0023 \\
\hline 18 & $14,3 \%$ & $35,7 \%$ & $21,4 \%$ & $25,0 \%$ & $3,6 \%$ & 2 & 10,09 & 0,0390 \\
\hline 19 & $21,4 \%$ & $32,1 \%$ & $21,4 \%$ & $14,3 \%$ & $10,7 \%$ & 2 & 4,73 & 0,3159 \\
\hline 20 & $10,7 \%$ & $39,3 \%$ & $35,7 \%$ & $14,3 \%$ & $0,0 \%$ & 2 & 9,52 & 0,0231 \\
\hline 21 & $10,7 \%$ & $10,7 \%$ & $28,6 \%$ & $39,3 \%$ & $10,7 \%$ & 4 & 12,32 & 0,0151 \\
\hline 22 & $14,3 \%$ & $21,4 \%$ & $14,3 \%$ & $28,6 \%$ & $21,4 \%$ & 4 & 2,50 & 0,6446 \\
\hline 24 & $17,9 \%$ & $42,9 \%$ & $28,6 \%$ & $10,7 \%$ & $0,0 \%$ & 2 & 8,76 & 0,0326 \\
\hline 25 & $14,3 \%$ & $39,3 \%$ & $28,6 \%$ & $17,9 \%$ & $0,0 \%$ & 2 & 5,71 & 0,1264 \\
\hline 26 & $14,3 \%$ & $35,7 \%$ & $35,7 \%$ & $14,3 \%$ & $0,0 \%$ & 2 & 6,86 & 0,0766 \\
\hline 27 & $10,7 \%$ & $7,1 \%$ & $35,7 \%$ & $42,9 \%$ & $3,6 \%$ & 4 & 22,59 & 0,0002 \\
\hline 28 & $14,3 \%$ & $25,0 \%$ & $17,9 \%$ & $42,9 \%$ & $0,0 \%$ & 4 & 7,24 & 0,0647 \\
\hline 29 & $17,9 \%$ & $28,6 \%$ & $39,3 \%$ & $10,7 \%$ & $3,6 \%$ & 3 & 14,11 & 0,0070 \\
\hline 30 & $14,3 \%$ & $57,1 \%$ & $17,9 \%$ & $10,7 \%$ & $0,0 \%$ & 2 & 20,95 & 0,0001 \\
\hline 31 & $3,6 \%$ & $32,1 \%$ & $17,9 \%$ & $39,3 \%$ & $7,1 \%$ & 4 & 16,79 & 0,0021 \\
\hline 32 & $14,3 \%$ & $25,0 \%$ & $25,0 \%$ & $32,1 \%$ & $3,6 \%$ & 4 & 8,75 & 0,0677 \\
\hline 33 & $10,7 \%$ & $32,1 \%$ & $32,1 \%$ & $21,4 \%$ & $3,6 \%$ & 2 & 11,43 & 0,0221 \\
\hline 34 & $14,3 \%$ & $17,9 \%$ & $42,9 \%$ & $25,0 \%$ & $0,0 \%$ & 3 & 7,24 & 0,0647 \\
\hline 35 & $17,9 \%$ & $39,3 \%$ & $25,0 \%$ & $14,3 \%$ & $3,6 \%$ & 2 & 12,32 & 0,0151 \\
\hline 36 & $21,4 \%$ & $32,1 \%$ & $32,1 \%$ & $14,3 \%$ & $0,0 \%$ & 2 & 3,43 & 0,3301 \\
\hline 37 & $10,7 \%$ & $32,1 \%$ & $39,3 \%$ & $14,3 \%$ & $3,6 \%$ & 3 & 15,89 & 0,0032 \\
\hline 39 & $21,4 \%$ & $32,1 \%$ & $14,3 \%$ & $28,6 \%$ & $3,6 \%$ & 2 & 9,20 & 0,0564 \\
\hline
\end{tabular}

Revista Produção Online. Florianópolis, SC, v. 18, n. 4, p. 1398-1421, 2018. 


\begin{tabular}{|c|c|c|c|c|c|c|c|c|}
\hline 40 & $10,7 \%$ & $14,3 \%$ & $53,6 \%$ & $17,9 \%$ & $3,6 \%$ & 3 & 26,61 & 0,0000 \\
\hline 41 & $7,1 \%$ & $17,9 \%$ & $25,0 \%$ & $50,0 \%$ & $0,0 \%$ & 4 & 14,86 & 0,0019 \\
\hline 42 & $10,7 \%$ & $35,7 \%$ & $25,0 \%$ & $28,6 \%$ & $0,0 \%$ & 2 & 4,95 & 0,1753 \\
\hline 43 & $17,9 \%$ & $39,3 \%$ & $21,4 \%$ & $21,4 \%$ & $0,0 \%$ & 2 & 4,19 & 0,2416 \\
\hline 44 & $7,1 \%$ & $25,0 \%$ & $35,7 \%$ & $32,1 \%$ & $0,0 \%$ & 3 & 7,24 & 0,0647 \\
\hline 45 & $10,7 \%$ & $28,6 \%$ & $39,3 \%$ & $21,4 \%$ & $0,0 \%$ & 3 & 6,48 & 0,0906 \\
\hline 46 & $10,7 \%$ & $35,7 \%$ & $35,7 \%$ & $14,3 \%$ & $3,6 \%$ & 2 & 15,45 & 0,0039 \\
\hline 47 & $14,3 \%$ & $17,9 \%$ & $39,3 \%$ & $21,4 \%$ & $7,1 \%$ & 3 & 10,09 & 0,0390 \\
\hline 48 & $3,6 \%$ & $17,9 \%$ & $35,7 \%$ & $28,6 \%$ & $14,3 \%$ & 3 & 10,98 & 0,0268 \\
\hline 49 & $7,1 \%$ & $53,6 \%$ & $14,3 \%$ & $25,0 \%$ & $0,0 \%$ & 2 & 18,67 & 0,0003 \\
\hline 50 & $7,1 \%$ & $25,0 \%$ & $28,6 \%$ & $35,7 \%$ & $3,6 \%$ & 4 & 13,66 & 0,0085 \\
\hline 51 & $3,6 \%$ & $32,1 \%$ & $25,0 \%$ & $35,7 \%$ & $3,6 \%$ & 4 & 16,79 & 0,0021 \\
\hline 52 & $7,1 \%$ & $39,3 \%$ & $28,6 \%$ & $25,0 \%$ & $0,0 \%$ & 2 & 8,00 & 0,0460 \\
\hline 53 & $7,1 \%$ & $28,6 \%$ & $25,0 \%$ & $35,7 \%$ & $3,6 \%$ & 4 & 13,66 & 0,0085 \\
\hline 54 & $7,1 \%$ & $35,7 \%$ & $25,0 \%$ & $28,6 \%$ & $3,6 \%$ & 2 & 13,66 & 0,0085 \\
\hline 55 & $3,6 \%$ & $25,0 \%$ & $35,7 \%$ & $25,0 \%$ & $10,7 \%$ & 3 & 11,43 & 0,0221 \\
\hline 56 & $3,6 \%$ & $28,6 \%$ & $35,7 \%$ & $25,0 \%$ & $7,1 \%$ & 3 & 13,66 & 0,0085 \\
\hline 57 & $10,7 \%$ & $46,4 \%$ & $21,4 \%$ & $17,9 \%$ & $3,6 \%$ & 2 & 18,57 & 0,0010 \\
\hline 58 & $50,0 \%$ & $21,4 \%$ & $25,0 \%$ & $3,6 \%$ & $0,0 \%$ & 2 & 16,38 & 0,0009 \\
\hline 59 & $14,3 \%$ & $25,0 \%$ & $35,7 \%$ & $21,4 \%$ & $3,6 \%$ & 3 & 10,09 & 0,0390 \\
\hline 60 & $3,6 \%$ & $25,0 \%$ & $50,0 \%$ & $17,9 \%$ & $3,6 \%$ & 3 & 25,71 & 0,0000 \\
\hline 61 & $10,7 \%$ & $28,6 \%$ & $32,1 \%$ & $25,0 \%$ & $3,6 \%$ & 3 & 10,54 & 0,0323 \\
\hline 62 & $3,6 \%$ & $28,6 \%$ & $35,7 \%$ & $32,1 \%$ & $0,0 \%$ & 3 & 9,52 & 0,0231 \\
\hline 63 & $0,0 \%$ & $35,7 \%$ & $46,4 \%$ & $10,7 \%$ & $7,1 \%$ & 3 & 16,38 & 0,0009 \\
\hline 64 & $0,0 \%$ & $32,1 \%$ & $46,4 \%$ & $17,9 \%$ & $3,6 \%$ & 3 & 15,24 & 0,0016 \\
\hline 65 & $7,1 \%$ & $14,3 \%$ & $39,3 \%$ & $25,0 \%$ & $14,3 \%$ & 3 & 10,98 & 0,0268 \\
\hline$F 0 n$
\end{tabular}

Fonte: Elaborado pelos autores (2017)

Dos itens representativos podemos perceber os itens $6,10,21,27,31,41,50$, 51 e 53, são os que receberam maior pontuação quanto ao grau de incidência, concluindo assim que são as barreiras que são consideradas mais presentes no setor analisado de acordo por um maior número de respondentes (funcionários do setor).

Neste estudo de caso exemplificativo, os itens foram referentes à barreira tecnológica falta de familiaridade e treinamento em sistemas; as barreiras pessoais resistência interna, medo de perder poder e falta e/ou comunicação ineficiente; e as barreiras organizacionais que foram a capacidade de acomodação, conflito de motivos, indisponibilidade de indivíduos, diferentes horários de trabalho e por fim os procedimentos, paradigmas e regras relacionados ao trabalho. 
Em uma segunda etapa investigou-se indícios da presença de uma estrutura de correlação entre as barreiras que pudesse simplificar a análise do conjunto das mesmas. O cálculo das correlações baseou-se no método de Spearman, que é adequado para verificar associações entre variáveis ordinais. Entre os itens que apresentaram a moda como representativa (de acordo com o critério estabelecido) para o grupo estudado, foram observadas correlações com valores acima de 0,6 e várias correlações significativas. Essas barreiras correlacionadas tendem a se comportar de maneiras parecidas, o que ajuda na forma de análise e trabalho futuro pela organização. O quadro 4 apresenta todas as correlações dos itens representativos acima de 0,6.

Quadro 4- Correlações identificadas entre os itens analisados

\begin{tabular}{|c|c|c|c|c|c|}
\hline \multicolumn{2}{|c|}{ Itens } & Correlação & \multicolumn{2}{c|}{ Itens } & Correlação \\
\hline Q1 & Q38 & 0,6 & Q31 & Q51 & 0,64 \\
\hline Q2 & Q63 & 0,63 & Q31 & Q53 & 0,67 \\
\hline Q6 & Q7 & 0,67 & Q33 & Q35 & $\mathbf{0 , 7 5}$ \\
\hline Q6 & Q8 & 0,64 & Q33 & Q37 & $\mathbf{0 , 7 6}$ \\
\hline Q6 & Q24 & 0,6 & Q33 & Q40 & 0,62 \\
\hline Q8 & Q21 & 0,61 & Q33 & Q52 & 0,72 \\
\hline Q8 & Q36 & 0,64 & Q33 & Q53 & 0,6 \\
\hline Q8 & Q40 & 0,62 & Q33 & Q54 & 0,6 \\
\hline Q13 & Q16 & 0,65 & Q33 & Q60 & 0,61 \\
\hline Q13 & Q18 & 0,63 & Q35 & Q37 & 0,66 \\
\hline Q18 & Q20 & 0,67 & Q35 & Q46 & 0,71 \\
\hline Q18 & Q21 & 0,72 & Q35 & Q59 & 0,61 \\
\hline Q20 & Q21 & $\mathbf{0 , 7 7}$ & Q35 & Q61 & 0,61 \\
\hline Q20 & Q24 & 0,68 & Q37 & Q41 & 0,64 \\
\hline Q20 & Q33 & 0,71 & Q38 & Q63 & 0,62 \\
\hline Q20 & Q65 & 0,63 & Q40 & Q65 & 0,63 \\
\hline Q21 & Q24 & 0,6 & Q46 & Q52 & 0,68 \\
\hline Q21 & Q27 & 0,68 & Q47 & Q55 & 0,65 \\
\hline Q21 & Q33 & 0,72 & Q49 & Q60 & 0,61 \\
\hline Q21 & Q37 & 0,6 & Q51 & Q53 & 0,61 \\
\hline Q21 & Q65 & 0,65 & Q51 & Q54 & 0,62 \\
\hline Q24 & Q30 & $0,71 ~$ & Q51 & Q59 & 0,72 \\
\hline Q24 & Q33 & $\mathbf{0 , 7 5}$ & Q52 & Q54 & 0,63 \\
\hline Q24 & Q35 & 0,66 & Q52 & Q59 & 0,64 \\
\hline Q24 & Q46 & 0,63 & Q52 & Q62 & 0,72 \\
\hline Q24 & Q52 & 0,64 & Q53 & Q59 & $0,61 ~$ \\
\hline Q27 & Q33 & $0,71 ~$ & Q53 & Q62 & $0,61 ~$ \\
\hline & & & & & \\
\hline
\end{tabular}




\begin{tabular}{|c|c|c|c|c|c|} 
Q27 & Q35 & 0,6 & Q54 & Q58 & 0,63 \\
\hline Q30 & Q33 & 0,68 & Q54 & Q59 & 0,6 \\
\hline Q30 & Q35 & 0,63 & Q54 & Q62 & $\mathbf{0 , 7 9}$ \\
\hline Q30 & Q50 & 0,66 & Q59 & Q61 & 0,69 \\
\hline Q30 & Q52 & 0,62 & Q59 & Q62 & 0,68 \\
\hline Q31 & Q50 & 0,61 & \multicolumn{3}{|l}{}
\end{tabular}

Fonte: Elaborado pelos autores (2017)

Pode-se observar que as correlações mais altas ocorreram entre as barreiras sobre os procedimentos, paradigmas e regras relacionados ao trabalho e as condições políticas e sociais (itens 54 e 56) que apresentaram grau de correlação de 0,79; seguido do Ceticismo para a partilha de conhecimentos/ Hábito de manter Conhecimento para si mesmo e o medo de perder poder (itens 20 e 21); A falta de sensibilidade com os outros e a falta de interesse (itens 33 e 37). E com correlação de 0,75 aparece novamente a falta de sensibilidade junto ao preconceito (itens 33 e 35) e junto ao medo de tornar-se redundante (itens 24 e 33). Percebe-se que para esse grupo, as barreiras mais correlacionadas entre si, estão dentro de uma mesma classificação, sejam elas pessoais ou organizacionais.

Dessa forma, foi possível verificar as correlações entre barreiras e é possível diminuir ainda mais o quadro de barreiras, já que algumas funcionam interligadas.

\section{CONCLUSÕES}

Objetivou-se com este estudo construir um framework que apresentasse as principais barreiras à GC, junto a sua descrição, classificação e autores que as identificaram e utilizaram em seus trabalhos. O uso desse framework permite uma rápida identificação das possíveis barreiras nas organizações, sendo fonte para um estudo destas em profundidade, auxiliando as pesquisas futuras, como também aplicações práticas.

A figura 2 apresenta um resumo esquemático de todas as barreiras presentes no quadro 2; a fim de facilitar a visualização. No total são 65 barreiras agrupadas em 9 barreiras tecnológicas, 34 barreiras pessoais, 19 barreiras organizacionais e 9 barreiras de categoria cruzada.

Figura 2: Barreiras a GC 


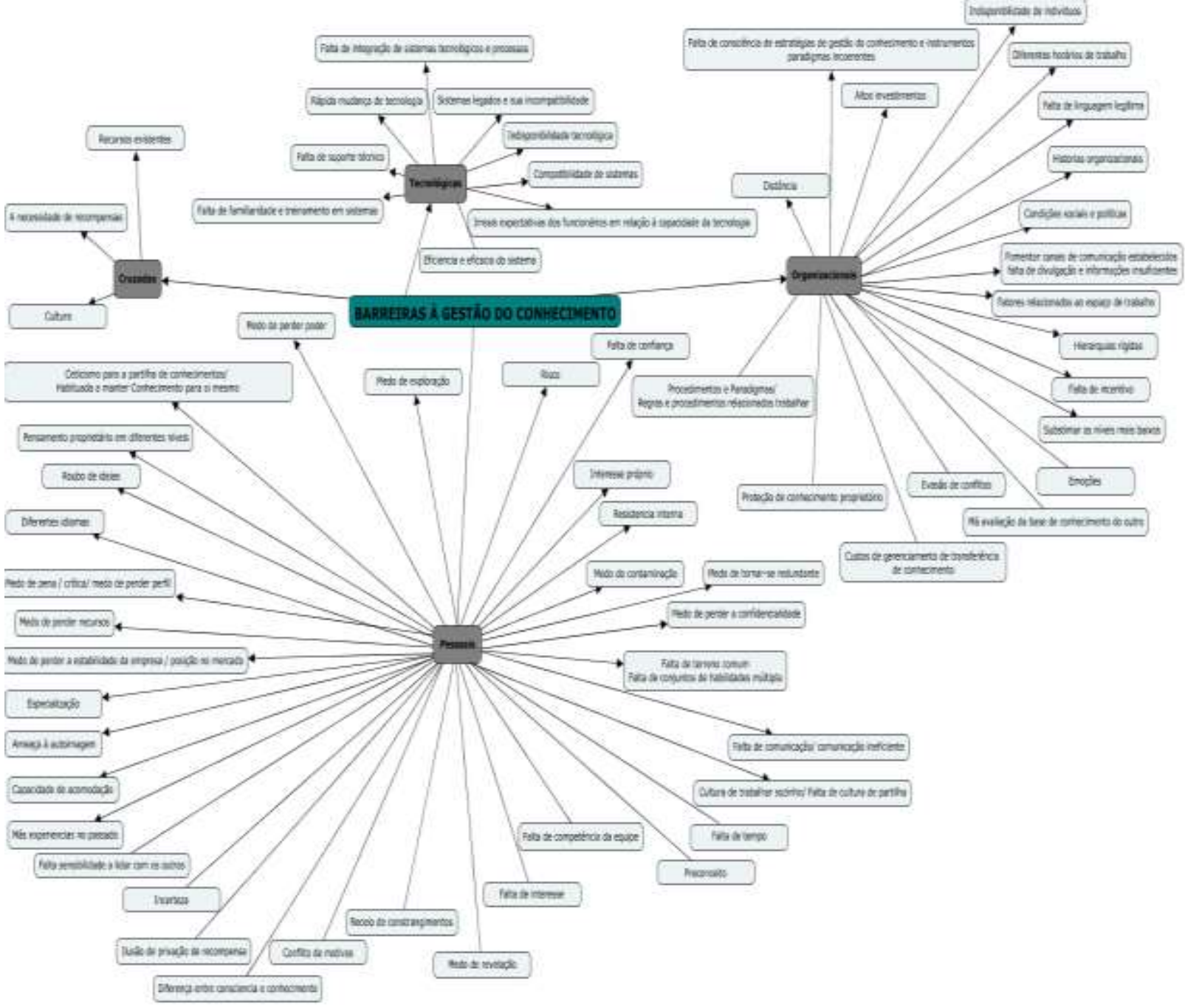

Fonte: Elaborado pelos autores (2017)

Essa figura esquemática pode ser ainda melhorada se forem utilizadas outras técnicas de mais robustez como equações estruturais, entretanto para rápidas aplicações, o framework atende.

O framework apresentado no quadro 2 foi testado com uma aplicação prática de identificação das barreiras que permeiam a GC, através de um estudo de caso em um setor administrativo de uma instituição pública de ensino superior no estado da Paraíba.

Os resultados da aplicação mostraram as barreiras cuja moda representativa é o valor 4 na escala Likert, ou seja, as que foram consideradas muito presentes pelos respondentes e são a maioria classificadas como organizacionais, seguindo para pessoais e por fim as tecnológicas, onde está presente apenas uma barreira. 
Com relação à correlação entre as barreiras que apresentou a moda representativa para o grupo estudado, foram observadas correlações com valores acima de 0,6 e várias correlações significativas (pelo teste de significância do coeficiente de correlação de Spearman), o que representa, nesse caso específico, um indício de que a análise pode ser simplificada definindo aspectos que contemple um número menor de itens.

No entanto, vale ressaltar que os resultados dessa aplicação são limitados exclusivamente para esse grupo analisado e não se pode generalizar os resultados, pois se tratava apenas de um caso ilustrativo do framework apresentado. Logo, sugere-se para trabalhos futuros que outros grupos sejam testados, para que seja possível identificar um padrão de correlações e seja possível criar novas categorias de itens de acordo com o grau de correlações.

Por fim, pode-se concluir que o framework construído utiliza técnicas estatísticas consagradas, mas apropriadas para a aplicação, tem sólida base teórica inicial, pois se pauta numa relação de barreiras conseguidas através de rastreamento científico robusto. Assim, ele auxilia de forma bastante simples na identificação das barreiras à GC que é o primeiro passo para que as organizações possam posteriormente desenvolver estratégias para minimizar seus efeitos ou sua eliminação a nível organizacional, o que é fundamental para que a empresa obtenha ganhos de desempenho através de uma estratégica e eficaz gestão do conhecimento, alcançando assim, maior satisfação dos stakeholders internos e externos.

\section{REFERÊNCIAS}

BARSON, R. J. et al. Inter-and intra-organizational barriers to sharing knowledge in the extended supply chain. In Proceedings of the e business and e work (e2000). Madrid, Spain, Oct.p.18-20, 2000.

BENMOUSSA CH. Barriers to Knowledge Management: A Theoretical Framework and a Review of Industrial Cases. World academy of science, engineering and technology. v.54, p.906-917, 2009.

BURES, V.: Cultural barriers in knowledge sharing, E+M Ekonomics and Management, Liberec, vol.6, special issue, p.57-62, 2003.

CASTRO, José Marcio de. Validade e confiabilidade em estudos de casos quantitativos. Minicurso ministrado na UFPB. 2017. 
COPETTI, F. DE A., SAURIN, T. A., SOLIMAN, M. Gestão de barreiras na implantação da produção enxuta: um estudo no setor automobilístico. Revista Produção Online, v.16, n. 1, p.313-341, 2016. DOI: http://dx.doi.org/10.14488/1676-1901.v16i1.2157

DAMODARAN, L., OLPHERT, W. Barriers and facilitators to the use of knowledge management systems. Behavior \& Information Technology, v.19, n.6, p. 405-413, 2000. DOI: http://dx.doi.org/10.1080/014492900750052660

DE LONG, D. W., FAHEY, L. Diagnosing cultural barriers to knowledge management. Academy of Management Perspectives, v.14, n.4, p. 113-127, 2000. DOI: https://doi.org/10.5465/ame.2000.3979820

DISTERER, G. Individual and social barriers to knowledge transfer. In: Proceedings of the 34th Hawaii international conference on system sciences, Hawaii, USA, January 36,2001.DOI: https://doi.org/10.1109/HICSS.2001.927138

DROR, I. E., MAKANY, T., KEMP, J. Overcoming learning barriers through knowledge management. Dyslexia, v.17, p.38-47, 2011. DOI: https://doi.org/10.1002/dys.419

HONG, D., SUH, E., KOO, C. Developing strategies for overcoming barriers to knowledge sharing based on conversational knowledge management: A case study of a financial company. Expert Systems with Applications, v. 38, n.12, p.14417-14427, 2011. DOI: https://doi.org/10.1016/j.eswa.2011.04.072

LEE.O. Psychological barriers to maintaining knowledge. Cyberpsychology \& Behavior, v.9, n.3, p. 123-132, 2006. DOI: https://doi.org/10.1089/cpb.2006.9.367

LIN, C., WU, J. C., YEN, D. C. Exploring barriers to knowledge flow at different knowledge management maturity stages. Information and Management, v.49, n.1, p.10-23, 2012. DOI: http://dx.doi.org/10.1016/j.im.2011.11.001

LOTTI OLIVA, F. Knowledge management barriers, practices and maturity model. Journal of Knowledge Management, v.18, n.6, p.1053-1074, 2014.

DOI: https://doi.org/10.1108/JKM-03-2014-0080

LUGGER, K., KRAUS, H. Mastering the human barriers in knowledge management. Journal of Universal Computer Science, v.7, n.6, p.488-497, 2001.

DOI: http://dx.doi.org/10.3217/jucs-007-06-0488

KROGH, G. V., ICHIJO, K., NONAKA, I. K. Facilitando a criação do conhecimento:

reinventando a empresa com o poder da inovação contínua. Rio de Janeiro: Campus, 2001.

MARODIN, G. A., SAURIN, T. A. Managing barriers to lean production implementation: context matters. International Journal of Production Research, v.53, n.13, p.3947-3962, 2015. DOI: https://doi.org/10.1080/00207543.2014.980454

MCLAUGHLIN, S., PATON, R. A., MACBETH, D. K. Barrier Impact on Organizational Learning within Complex Organizations. Journal of Knowledge Management, v.12, n.2, p.107-123, 2008. DOI: https://doi.org/10.1108/13673270810859550

MICHELON, M. J. et al. A criação do conhecimento corporativo promovido pelos fluxos de informações gerados na implantação do planejamento estratégico. Revista Produção Online, v. 6, n. 1, Florianópolis, 2006. DOI: http://dx.doi.org/10.14488/1676-1901.v6i1.89 
MILOSZ, M., MILOSZ, E. Critical success factors and barriers to implementation of knowledge management systems at Polish SMEs. Actual Problems of Economics, v.6, p.309-315, 2010.

MUNIZ Jr., J.; NAKANO, D. N., Gestão do Conhecimento em Sistemas Produtivos. In: OLIVEIRA, V. F.; CAVENAGHI, V.; Másculo F. S., (Org.). Tópicos Emergentes e Desafios Metodológicos em Engenharia de Produção: casos, experiência e proposições. 1. ed. Rio de Janeiro: ABEPRO, 2009, v. 2, p. 131-203.

PATIL, S. K., KANT, R. A fuzzy AHP-TOPSIS framework for ranking the solutions of Knowledge Management adoption in Supply Chain to overcome its barriers. Expert Systems with Applications, v.41, n.2, p.679-693, 2014. DOI: http://dx.doi.org/10.1016/j.eswa.2013.07.093

PIRKKALAINEN, H., PAWLOWSKI, J. M. Global social knowledge management Understanding barriers for global workers utilizing social software. Computers in Human Behavior, v.30, p.637-647, 2014. DOI: http://dx.doi.org/10.1016/j.chb.2013.07.041

RAS, E., MEMMEL, M., WEIBELZAHL, S. Integration of e-learning and knowledge management - Barriers, solutions and future issues. Professional Knowledge Management, v.3782, p.155-164, 2005.DOI: https://doi.org/10.1007/11590019 19

REIS, Z. C., MILAN, G. S. GC: um desafio a ser administrado. Revista Produção Online, v.9, n.1, p.73-94, 2009. DOI: http://dx.doi.org/10.14488/1676-1901.v9i1.200

RIEGE, A. Three-dozen Knowledge-Sharing Barriers Managers Must Be Consider. Journal of Knowledge Management, v.9, p.18-35, 2005. DOI: https://doi.org/10.1108/13673270510602746

RODRÍGUEZ-GÓMEZ, D., GAIRÍN, J. Unravelling knowledge creation and management in educational organizations: barriers and enablers. Knowledge Management Research \& Practice, v.13, n.2, p.149-159, 2013. DOI: https://doi.org/10.1057/kmrp.2013.37

SHAHMORADI, L.et al. Knowledge Sharing as a Powerful Base for Management. The Health Care Manager, v.36, n.2, p.176-183, 2017. DOI:

https://doi.org/10.1097/HCM.0000000000000150

STEFANOVITZ, J. P., SEIDO NAGANO, M. Aquisição e criação de conhecimento na indústria de alta tecnologia. Revista Produção Online, v.6. n. 1, 2007.

DOI: http://dx.doi.org/10.14488/1676-1901.v6i1.87

SZEZERBICKI, A. S.et al.. GC em equipes de alta performance: o caso do Clube Atlético Paranaense. Revista Produção Online, v.6, n.2, p.01-25, 2006.

DOI: http://dx.doi.org/10.14488/1676-1901.v6i2.287

SZULANSKI, G. Exploring internal stickiness: impediments to the transfer of best practice within the firm. Strategic Management Journal, v. 17, p. 27-43, 1996.

DOI: https://doi:10.1002/smj.4250171105

THOBEN, K.-D., WEBER, F., WUNRAM, M., Barriers in Knowledge Management and Pragmatic Approaches. Studies in Informatics and Control, v 11, n.1, p. 7-15, 2002. 
VALMOHAMMADI, G., GHASSEMI, A. Identification and prioritization of the barriers of knowledge management implementation using Fuzzy Analytical Network Process; a case study of the Iranian context Abstra. VINE Journal of Information and Knowledge Management Systems, 2016. DOI: https://doi.org/10.1108/VJIKMS-08-2015-0046

WUNRAM, M., FOSTER, G., MOTTAGHIAN, S. Deliverable D06 - Identification of Barriers. Result from the project CORMA - Practical Methods and Tools for Corporate Knowledge Management. Projekt Nr. IST-1999-12685. Unpublished. 2000.

HANWK, S., ZHEND, W., ZMUD, R.W., Overcoming Knowledge-Transfer Barriers in Infrastructure Management Outsourcing: Lessons from a Case Study. MIS Quarterly Executive, v.10, n.1, 2009.

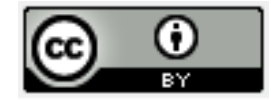

Artigo recebido em: 21/09/2017 e aceito para publicação em: 01/12/2017 DOI: http://dx.doi.org/10.14488/1676-1901.v18i4.3007 